\title{
Triptolide-induced in vitro and in vivo cytotoxicity in human breast cancer stem cells and primary breast cancer cells
}

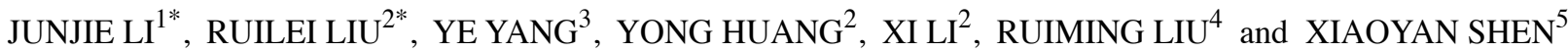 \\ ${ }^{1}$ Department of Breast Surgery, Sichuan Cancer Hospital, Chengdu 610041; ${ }^{2}$ Department of Breast Surgery, \\ Third Affiliated Hospital of Sun Yat-sen University, Guangzhou 510630; ${ }^{3}$ Department of Pulmonary Tumor, \\ Sichuan Cancer Hospital, Chengdu 610041; ${ }^{4}$ Laboratory of Surgery, The First Affiliated Hospital of \\ Sun Yat-sen University, Guangzhou 510080; ${ }^{5}$ Laboratory of Pharmacology and Toxicology, \\ College of Pharmacy, Sun Yat-sen University, Guangzhou 510006, P.R. China
}

Received January 28, 2014; Accepted March 7, 2014

DOI: 10.3892/or.2014.3115

\begin{abstract}
We investigated the potential efficacy of the Chinese herbal extract triptolide for the treatment of human breast cancer by measuring the triptolide-induced cytotoxicity in cultures of human primary breast cancer cells (BCCs) and breast cancer stem cells (BCSCs) in vitro and in vivo. Human BCCs and BCSCs from invasive ductal carcinoma samples were cultured and treated with $0.1,0.5$ or $1.0 \mu \mathrm{M}$ triptolide. Cell death and apoptosis were measured after 24, 48 and $72 \mathrm{~h}$ of treatment. Mammospheres were found to be highly tumorigenic when implanted subcutaneously in nude BALB/c mice. Triptolide was cytotoxic against both human primary $\mathrm{BCCs}$ and $\mathrm{BCSCs}$ in vitro $(\mathrm{P}<0.05)$, but the cytotoxicity was stronger against the $\mathrm{BCCs}$. In response to $1 \mu \mathrm{M}$ triptolide for $72 \mathrm{~h}$, the apoptotic rates were approximately $60 \%$ for BCCs and $30 \%$ for BCSCs. The BCSCs exhibited a high formation rate of tumors when implanted subcutaneously in nude BALB/c mice. Triptolide treatment in vivo significantly inhibited tumor growth compared with mock treatment. In conclusion, the cytotoxicity of triptolide against BCCs and BCSCs in vitro and in vivo suggests that this natural diterpenoid triepoxide compound may have clinical applications for the suppression of breast tumor growth.
\end{abstract}

\section{Introduction}

Breast cancer is the most common malignant tumor in women. The risk of breast cancer is influenced by multiple factors, including family and childbearing histories, hormone levels, obesity and diabetes mellitus. Cancer stem cells, first isolated

Correspondence to: Dr Xiaoyan Shen, Laboratory of Pharmacology and Toxicology, College of Pharmacy, Sun Yat-sen University, Guangzhou 510006, P.R. China

E-mail: shxiaoy@mail.sysu.edu.cn

"Contributed equally

Key words: breast cancer cells, breast cancer stem cells, triptolide, apoptosis from acute leukemia patients in 1997 (1), may lead to treatment resistance and the high metastatic potential of tumors. Al-Hajj et al (2) reported that as few as 100 cells with the expression profile $\mathrm{CD} 44^{+} \mathrm{CD} 24^{-/ \text {low }} / \mathrm{Lin}^{-}$, now known to be indicative of the stem cell phenotype, were able to form tumors in severely immunodeficient nude mice and to give rise to tumorigenic breast cells. Stem cells are characterized by high chemotherapy and radiotherapy resistance, tolerance to hypoxia, and high oncogenicity, invasiveness and metastatic potential. These characteristics greatly enhance the risk for local recurrence and distant metastasis. Therefore, the destruction of cancer stem cells is critical for effective long-term cancer treatment.

Triptolide is extracted from the root of Tripterygium wilfordii. It has been reported to have various pharmacological effects such as anti-inflammation, anti-oxidant and anti-angiogenesis (3). In particular, the antitumor activity of triptolide has attracted the most interest (4). It was found to effectively induce prostate and bile duct cancer cell apoptosis, and to inhibit the growth and metastasis of these tumor cells (5). It is also the most effective chemotherapeutic drug for monocytic and myelocytic leukemia, increasing the remission rates to 71 and $87 \%$, respectively (6). This antitumor effect was found to be associated with the downregulation of cyclin and anti-apoptosis genes and with the upregulation of pro-apoptosis genes (7). In addition, triptolide was found to downregulate expression of the transcription factor $\mathrm{NF}-\kappa \mathrm{B}$ in multiple myeloma (8). However, the observations were mainly carried out in tumor cell lines and primary tumor cells, while the effects of triptolide on tumor stem cells remain largely unknown. In this study, we investigated the cytotoxicity of triptolide in both human primary breast cancer cells (BCCs) and breast cancer stem cells (BCSCs) in order to explore the clinical potential of triptolide for breast cancer treatment.

\section{Materials and methods}

Major reagents and devices. The following reagents and devices were used: fetal bovine serum (FBS), DMEM-F12, DMEM, B27, trypsin, collagenase I, streptomycin + benzylpenicillin (all from Gibco-BRL, Gaithersburg, MD, USA); 
oct4 and sox 2 antibodies (Santa Cruz Biotechnology, Santa Cruz, CA, USA); CD24-PE and CD44-FITC monoclonal antibodies (Beckman Coulter, Brea, CA, USA); reverse transcription kits (Toyobo, Osaka, Japan); alkaline fibroblastic growth factor (bFGF) and epidermal growth factor (EGF) (Peprotech, Rocky Hill, NJ, USA); human and bovine insulin as well as hyaluronidase (all from Sigma, St. Louis, MO, USA); 99.7\% triptolide (Pharmaceutical Sciences, Sun Yat-sen University, Guangzhou, China); apoptosis detection kits (BD, USA), CCK-8 cell viability kits (Dojindo Laboratories, Kumamoto, Japan); a flow cytometer (BD, USA); a constant $\mathrm{CO}_{2}$ cell culture incubator (Thermo Fisher Scientific, USA); an inverted fluorescence microscope (Nikon TE 2000-U; Nikon, Tokyo, Japan) and a Coulter counting plate.

Isolation and cultivation of tumorigenic breast cancer stem cells. Tumorigenic breast cancer cells were isolated from the invasive ductal carcinoma samples, which have been described in the literature (9). Briefly, cell suspensions were cultured at a density of $1 \times 10^{5} / \mathrm{ml}$ in stem cell culture medium DMEM-F12 containing $2 \times 10^{-5} \mathrm{~g} / 1 \mathrm{EGF}, 5 \times 10^{-3} \mathrm{~g} / 1$ insulin, $1 \times 10^{-5} \mathrm{~g} / 1 \mathrm{bFGF}$ and $\mathrm{B} 27$ at $37^{\circ} \mathrm{C}$ under a $5 \% \mathrm{CO}_{2}$ atmosphere with saturated humidity. The medium was exchanged every 2 to 3 days. After 7 to 9 days, mammospheres of $\sim 100 \mu \mathrm{m}$ in diameter were observed. The mammospheres were digested with trypsin solution containing $0.05 \%$ EDTA for 5 to $10 \mathrm{~min}$ and filtered through a 400-mesh screen. The resulting cell suspension was cultured in stem cell culture medium, and the cell phenotype was characterized as described below.

Cultivation of primary breast cancer cells. Mammospheres were digested as described and the suspension was cultured in DMEM with $5 \% \mathrm{FBS}$ at $37^{\circ} \mathrm{C}$ under a $5 \% \mathrm{CO}_{2}$ atmosphere with saturated humidity. The culture medium was exchanged every 2 to 3 days. Cells in the logarithmic growth phase were digested with $0.25 \%$ trypsin and collected for experiments.

Identification of breast cancer stem cells

Detection of CD44 and CD24 expression. Mammospheres (cultured for 7 to 9 days) were digested to a single-cell suspension and then resuspended in PBS containing 2.5\% FBS. Both CD44-FITC and CD24-PE antibodies were added at $20 \mu 1$ per $1 \times 10^{6}$ cells, and the suspension was incubated for $30 \mathrm{~min}$ on ice under darkness. The labeled cells were rinsed with PBS containing 2.5\% FBS and fixed in PBS containing $10 \mathrm{mg} / \mathrm{ml}$ paraformaldehyde. Fixed and stained cells were examined for CD44/24 expression by flow cytometry. Control cultures were processed identically except for the addition of the antibodies.

Detection of sox2, oct4 and nanog expression. Levels of nanog, sox 2 and oct 4 mRNA and proteins in the mammospheres were measured by immunofluorescence and semi-quantitative RT-PCR. The primer sequences of nanog, sox 2 , oct 4 and $\beta$-actin are as follows: nanog forward, 5'-GTC TTCTGCTGAGATGC-3' and reverse, 5'-AGTTGTTTT TCTGCCACC-3'; sox2 forward, 5'-TGCAGTACAACTCCA TGACCA-3' and reverse, 5'-GTGCTGGGACATGTGAAG TCT-3'; oct4 forward, 5'-CTCCTGAAGCAGAAGAGGAT CAC-3' and reverse, 5'-CTTCTGGCGCCGGTTACAGAA CCA-3'; $\beta$-actin forward, 5'-CATGTACGTTGCTATCCA GGC-3' and reverse, 5'-CTCCTTAATGTCACGCACGAT-3'.
Cytotoxicity assays

CCK-8 cell viability assay. Single-cell suspensions from the digested mammospheres were cultured for one day on 96-well plates at $37^{\circ} \mathrm{C}$ under $5 \% \mathrm{CO}_{2}$ and saturated humidity. The culture medium was replaced with the same medium containing $0.1,0.5$ or $1 \mu \mathrm{M}$ triptolide and treated for 24,48 and $72 \mathrm{~h}$. Colorimetric assays were performed $3 \mathrm{~h}$ after CCK-8 was added. Control cells were treated with DMSO (vehicle) instead of triptolide. The OD value was measured, and the percentage of dead cells was calculated using the following formula: $100 \% \times$ (OD of the control group - OD of the experimental group)/OD of the control group. The experiment was repeated 3 times using three independent cultures.

Apoptosis assay. Cells cultured on 96-well plates were treated with $0.1,0.5$ or $1 \mu \mathrm{M}$ triptolide (or vehicle) and assayed after 24, 48 and $72 \mathrm{~h}$. Adherent cells were washed twice with PBS prior to and following digestion with $0.25 \%$ trypsin. Then, $100 \mu \mathrm{l}$ binding buffer and $5 \mu \mathrm{l}$ FITC-labeled Annexin V were added at room temperature under darkness. Thirty minutes later, $5 \mu \mathrm{l}$ PI was added $(50 \mu \mathrm{g} / \mathrm{ml})$. After $5 \mathrm{~min}, 400 \mu \mathrm{l}$ binding buffer was added. The proportion of apoptotic cells was assayed by flow cytometry. For cells in suspension, the suspended microsphere cells digested to cell suspension were labeled as described above; except that $10 \mu$ FITC-labeled Annexin V was added.

Animal studies. Mammosphere cells $\left(1 \times 10^{5}\right)$ were implanted in the left flank of 5-week-old female BALB/c nude mice. Cells treated with triptolide (concentration $1 \mu \mathrm{M}$ ) before implantation did not form tumors $(n=10$; followed up until day 70 ). When the tumors reached $\sim 5 \mathrm{~mm}$ in maximal diameter, triptolide $(1 \mu \mathrm{M})$ or PBS (mock) was intravenously injected into the nude mice (day 0 ), followed by repeated injections on days 3, 7, 10 and 14. Tumor volumes were measured twice a week using an external caliper, and the tumor volume (V) was calculated as follows: $\mathrm{V}=$ length $\mathrm{x}$ width $\mathrm{x}$ height.

All animal procedures were approved by the Animal Care and Use Committee of Sun Yat-Sen University.

Statistical analyses. The statistical program SPSS 13.0 was used for all analyses. The proportion of apoptotic cells was compared between the vehicle- and triptolide-treated groups using the Chi-square test. A $\mathrm{P}<0.05$ was considered to indicate a statistically significant difference.

\section{Results}

Cultivation and isolation of primary breast cancer cells and breast cancer stem cells. BCCs isolated from invasive ductal carcinoma samples formed mammospheres after 7 to 9 days in a serum-free stem cell selective medium (Fig. 1A). Mammospheres were digested with $2.5 \%$ trypsin to obtain a single-cell suspension for phenotype analysis. Flow cytometry revealed that the majority of mammosphere cells $(95 \pm 0.5 \%)$ were $\mathrm{CD} 44^{+} \mathrm{CD} 24^{-/ \text {low }}$ (Fig. 1B), consistent with a stem cell phenotype. After mammospheres were cultured in DMEM + 5\% FBS (Fig. 2A); however, surviving cells adhered to the substrate and the proportion of CD $44^{+} \mathrm{CD} 24^{-/ \text {low }}$ cells decreased from 98 to 5\% (Fig. 2B), suggesting differentiation of BCSCs into primary BCCs. Mammospheres also expressed 
A

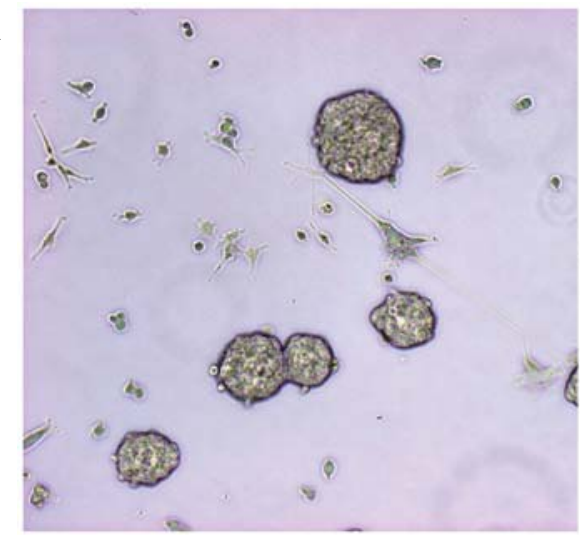

B

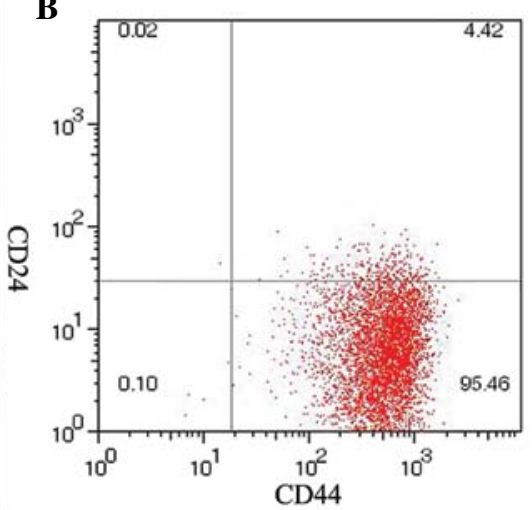

Figure 1. Appearance of the human mammospheres and surface antigen expression. (A) A microscopic image showing typical primary mammospheres (magnification $\mathrm{x} 100$ ). (B) Flow cytometry scatter plot showing that the majority of mammosphere cells were CD $44^{+} \mathrm{CD} 24^{-/ l o w}$ (95.46\% of cells are in the bottom right quadrant).

A

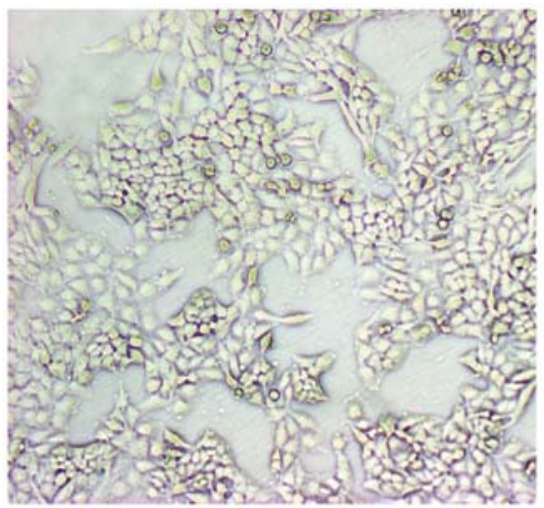

B

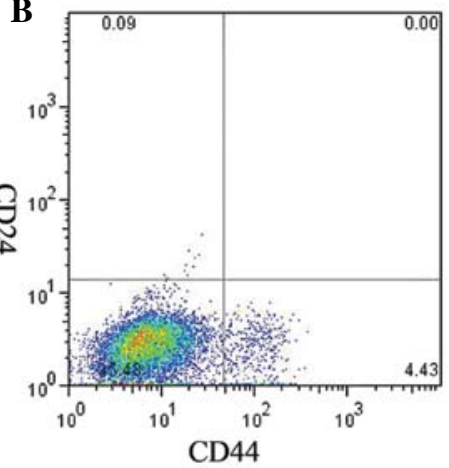

Figure 2. Appearance of primary human breast cancer cells and surface antigen expression. (A) A microscopic image of the adherent cells derived from the mammospheres and cultured in serum-containing media (magnification, x100). (B) Flow cytometry scatter plot showing that most of the cells were $\mathrm{CD} 44 \mathrm{CD} 24^{- \text {llow }}$ (95.57\% of cells are in the bottom left quadrant).

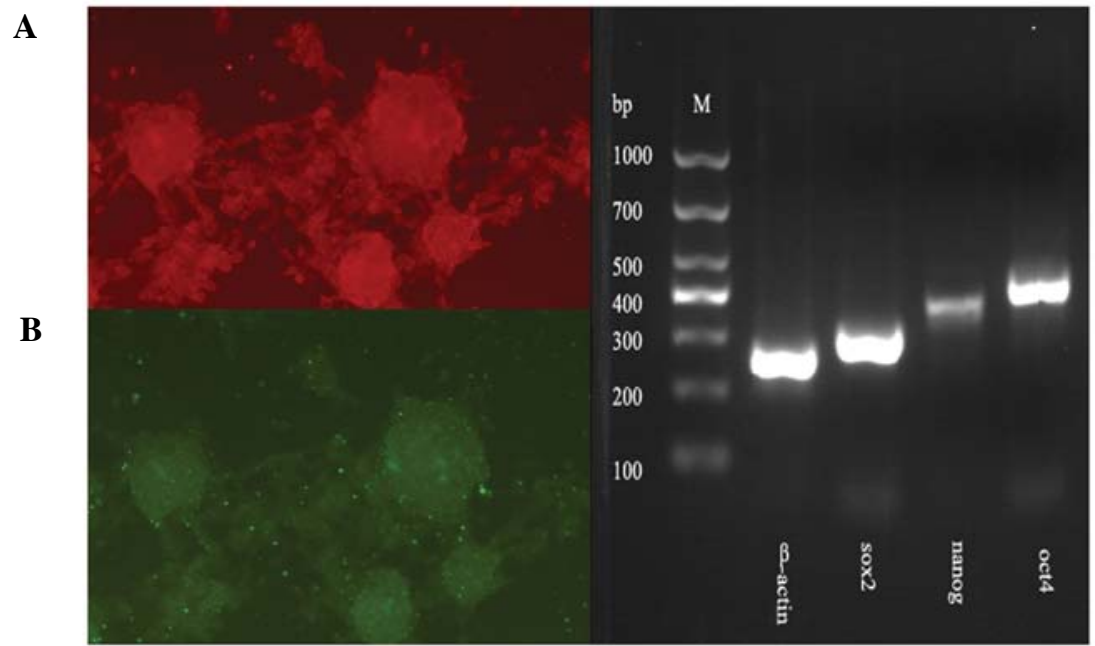

Figure 3. Expression of stem cell markers by human mammospheres. Immunofluorescence staining for (A) oct4 and(B) sox 2 expression in mammospheres (magnification x100). (C) Expression of sox 2, nanog and oct4 mRNA in mammospheres as detected by RT-PCR. $\beta$-actin served as a control for total RNA.

the stem cell markers sox 2 , oct 4 and nanog at both the protein and mRNA levels (Fig. 3), confirming that the mammospheres contained BCSCs.
Cytotoxic effect of triptolide on human primary breast cancer cells and breast cancer stem cells. Triptolide was cytotoxic to both primary BCCs and BCSCs at $0.1,0.5$ and $1 \mu \mathrm{M}$. Cell 


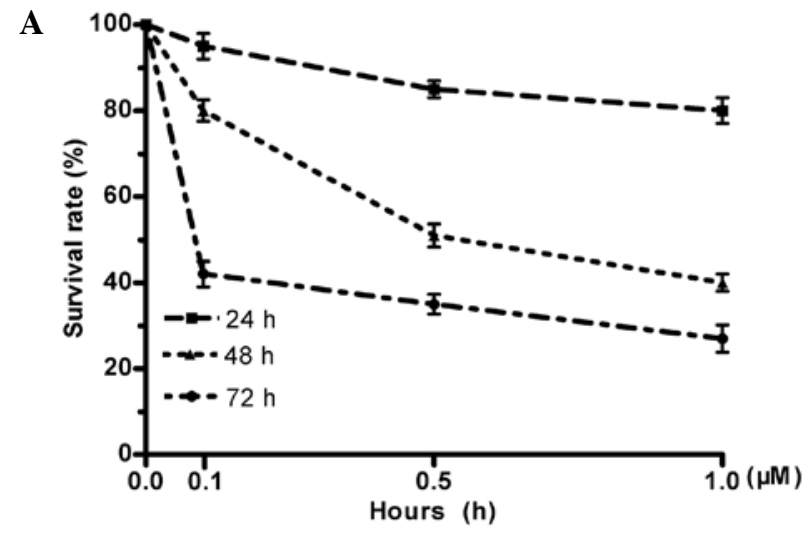

Figure 4. Cytotoxicity of triptolide on primary human breast cancer cells as a percentage of the vehicle-treated controls.

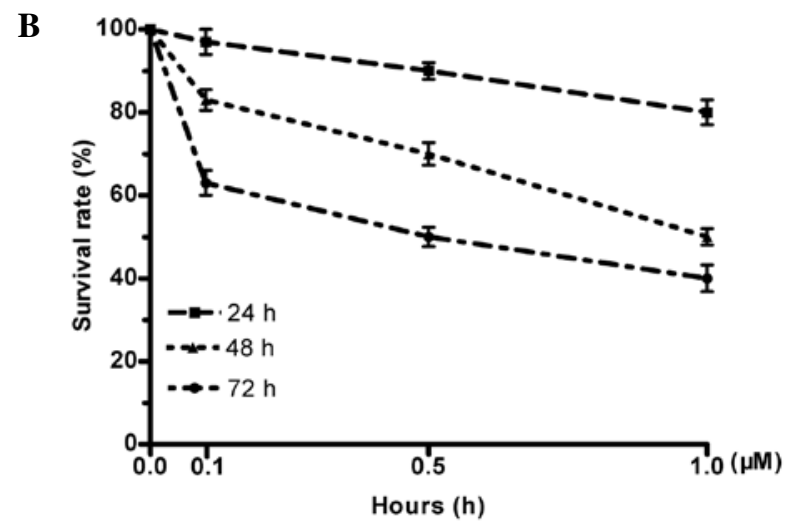

Figure 5. Cytotoxicity of triptolide in human breast cancer stem cells as a percentage of the vehicle-treated controls.

death increased with incubation time at all concentrations tested in both cancer cell types (Figs. 4 and 5). After $72 \mathrm{~h}$, the death rate of the BCCs relative to vehicle-treated controls was $33.1 \pm 2.7 \%$ at $0.1 \mu \mathrm{M}, 49.3 \pm 3.5 \%$ at $0.5 \mu \mathrm{M}$ and $65.6 \pm 5.2 \%$ at $1 \mu \mathrm{M}$ of triptolide. Triptolide was significantly less toxic against BCSCs; however, the percentage of death relative to vehicle-treated BCSCs was $15.5 \pm 2.3 \%$ at $0.1 \mu \mathrm{M}, 22.8 \pm 3.7 \%$ at $0.5 \mu \mathrm{M}$ and $37.9 \pm 3.9 \%$ at $1 \mu \mathrm{M}$ triptolide after $72 \mathrm{~h}$ (Fig. 5).

Induction of apoptosis by triptolide. Consistent with results from the CCK-8 measurement, the proportion of apoptotic cells gradually increased over time and with increasing concentrations of triptolide in both primary BCCs and BCSCs. After $72 \mathrm{~h}, 26.1 \pm 1.9 \%$ of BCCs were apoptotic at $0.1 \mu \mathrm{M}, 40.3 \pm 2.7 \%$ at $0.5 \mu \mathrm{M}$ and $56.5 \pm 4.6 \%$ at $1 \mu \mathrm{M}$ triptolide compared to only $3.1 \% \pm 1.5 \%$ of BCCs treated with vehicle $(\mathrm{P}<0.05)$ (Fig. 6). The proportion of early apoptotic BCCs was $13.3 \pm 1.1 \%$ at $0.1 \mu \mathrm{M}, 20.1 \pm 2.1 \%$ at $0.5 \mu \mathrm{M}$ and $23.5 \pm 2.6 \%$ at $1 \mu \mathrm{M}$ triptolide compared to only $1.5 \pm 1.0 \%$ of BCCS treated with vehicle $(\mathrm{P}<0.05)$ (Fig. 6F). Also consistent with the lower cytotoxicity of triptolide against BCSCs, the percentage of apoptosis was $7.9 \pm 2.3 \%$ at $0.1 \mu \mathrm{M}, 19.8 \pm 3.2 \%$ at $0.5 \mu \mathrm{M}$ and $31.3 \pm 2.7 \%$ at $1 \mu \mathrm{M}$ triptolide, significantly lower than that in the BCCs $(\mathrm{P}<0.05)$, but still significantly higher than that in the vehicletreated BCSCs $(1.9 \pm 1.3 \%)(\mathrm{P}<0.05)($ Fig. 7$)$; the proportion of early apoptotic BCCs was $5 \pm 1.2 \%$ at $0.1 \mu \mathrm{M}, 13 \pm 1.5 \%$ at
A

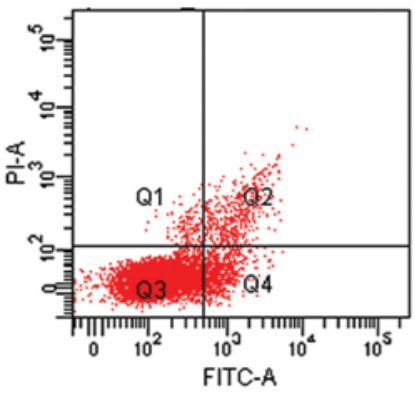

B
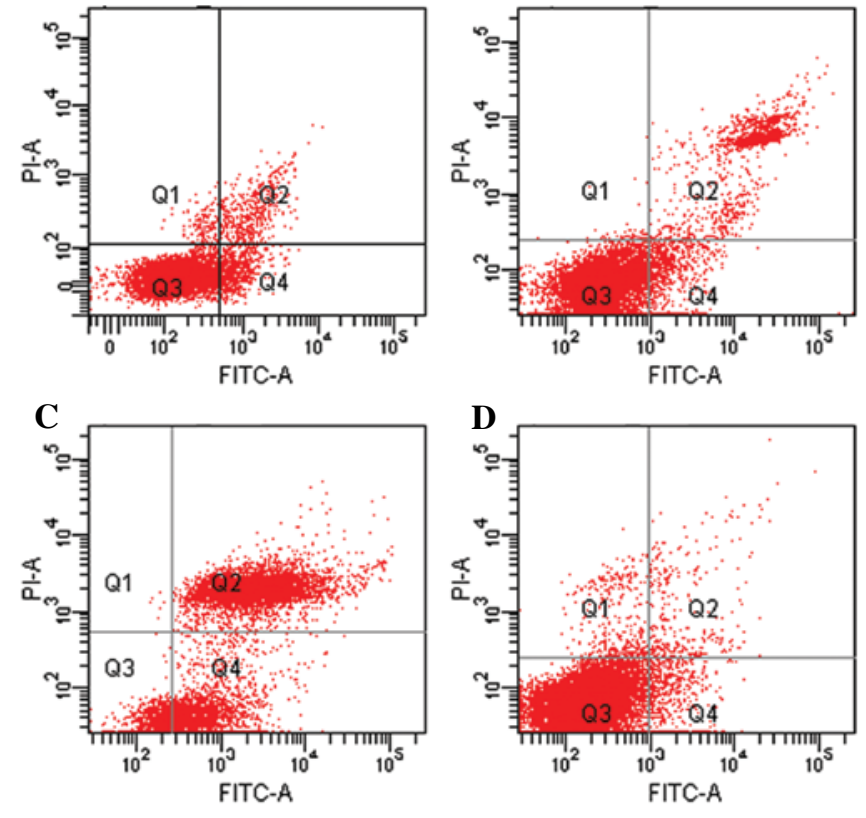

$\mathbf{E}$

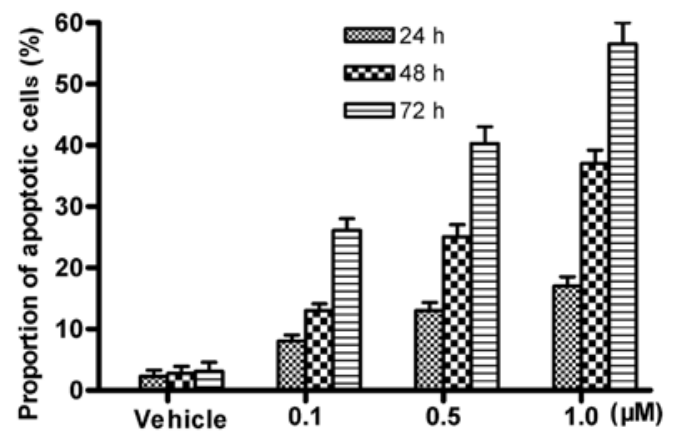

$\mathbf{F}$

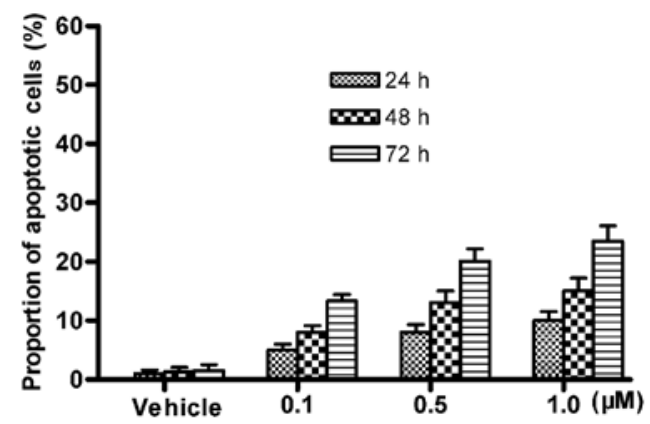

Figure 6. Induction of apoptosis in primary human breast cancer cells by triptolide. Human primary breast cancer cells were incubated with triptolide at (A) $0.1 \mu \mathrm{M}$, (B) $0.5 \mu \mathrm{M}$ and (C) $1 \mu \mathrm{M}$ for $72 \mathrm{~h}$. (D) The control group was incubated in vehicle (DMSO). The apoptotic rate was determined by counting the number of cells positive for Annexin V (FITC-A, y-axis) and propidium iodide (PI, $\mathrm{x}$-axis). A high density of red dots in Q2 (Annexin $\mathrm{V}^{+} \mathrm{PI}^{+}$) indicates a greater proportion of apoptotic cells. (E and $\mathrm{F}$ ) The apoptotic rates were significantly higher in triptolide-treated BCCs than in the vehicle-treated BCCs $(\mathrm{P}<0.05$, Chi-square test).

$0.5 \mu \mathrm{M}$ and $19 \pm 2.1 \%$ at $1 \mu \mathrm{M}$ triptolide compared to only $0.9 \pm 0.6 \%$ of BCSCs treated with vehicle $(\mathrm{P}<0.05)($ Fig. $7 \mathrm{~F})$

Treatment of tumors in vivo. Mammospheres were used to form tumors when injected into the mammary fat pad of 5-week-old female nude BALB/c mice. Cells incubated with triptolide at $1 \mu \mathrm{M}$ before implantation did not form tumors 
A

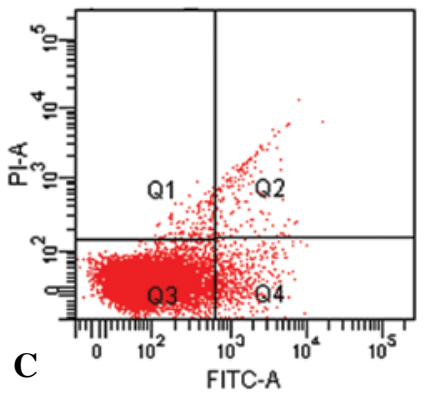

B
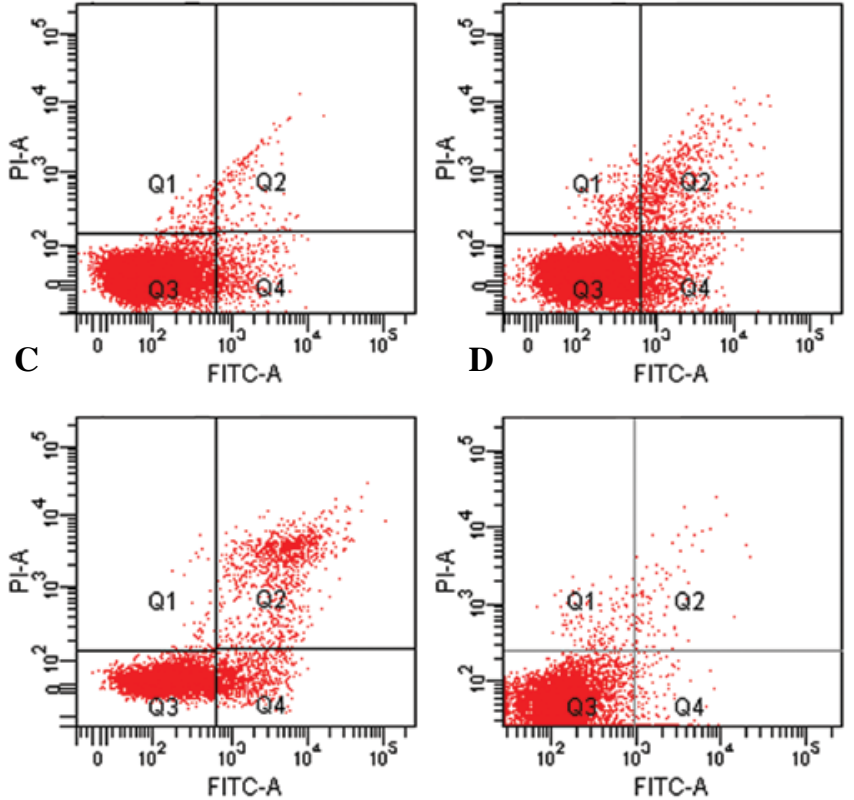

$\mathbf{E}$

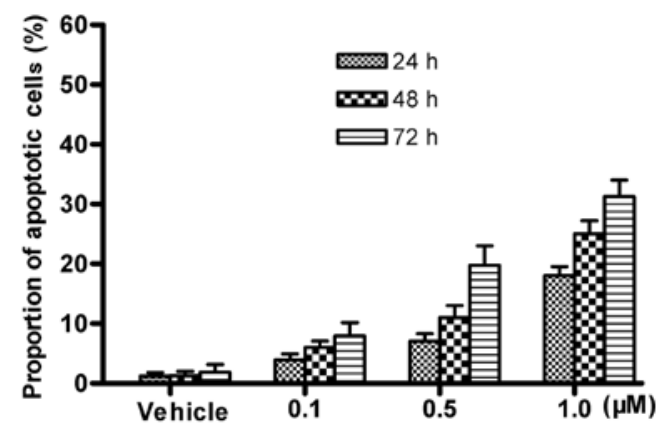

$\mathbf{F}$

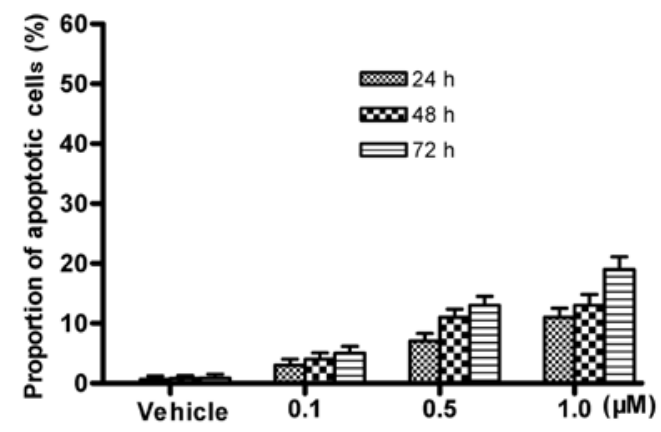

Figure 7. Induction of apoptosis in human breast cancer stem cells by triptolide. Human breast cancer stem cells were incubated with triptolide at (A) $0.1 \mu \mathrm{M}$, (B) $0.5 \mu \mathrm{M}$ and (C) $1 \mu \mathrm{M}$ for $72 \mathrm{~h}$. (D) The control group was incubated in vehicle (DMSO). The apoptotic rate was determined by counting the number of cells positive for Annexin V (FITC-A, y-axis) and propidium iodide (PI, $\mathrm{x}$-axis). A high density of red dots in Q2 (Annexin $\mathrm{V}^{+} \mathrm{PI}^{+}$) indicates a greater proportion of apoptotic cells. (E and F) The apoptotic rates were significantly higher in triptolide-treated BCSCs than in the vehicle-treated BCSCs $(\mathrm{P}<0.05$, Chi-square test).

( $\mathrm{n}=15$; observation until day 70 ). To assess the antitumor efficacy of triptolide, when the tumors were $\sim 5 \mathrm{~mm}$ in maximal diameter, triptolide $(1 \mu \mathrm{M})$ or PBS (mock) was intravenously injected into nude mice on days $0,3,7,10$ and 14. After 15 days, the tumors began to have a trend of reduced volume.
$\mathbf{A}$

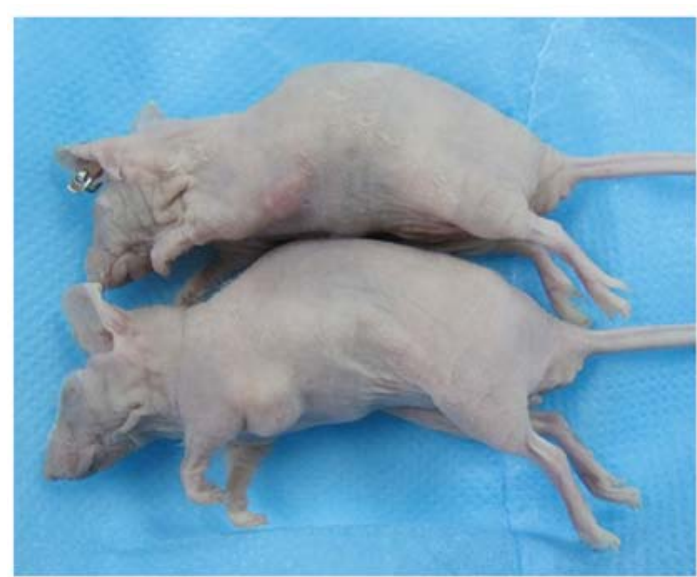

B

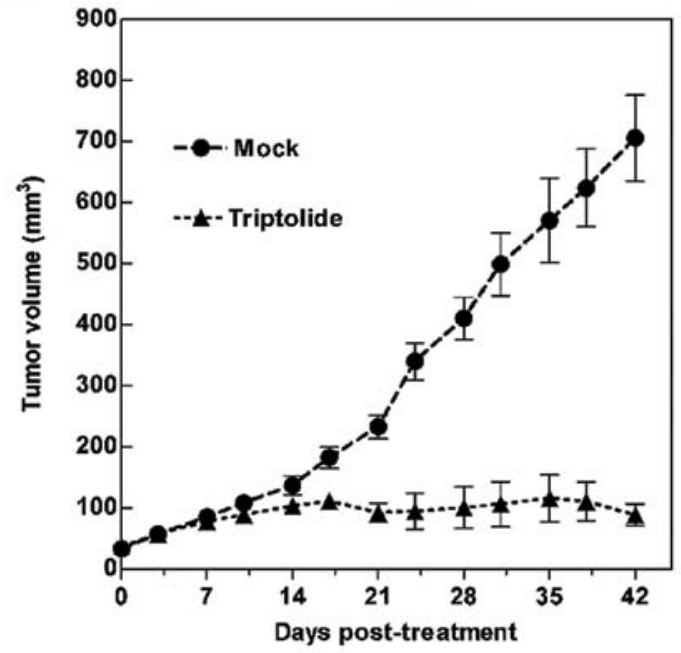

Figure 8. Treatment of subcutaneous tumors with triptolide.(A) Representative images of tumors from triptolide-treated (upper) or mock-treated (lower) mice 40 days following treatment. (B) Triptolide was intravenously injected into nude mice on days $0,3,7,10$ and 14 . After 21 days, the tumors began to exhibit a tendency to decrease in volume. Tumor size was measured twice a week, and the tumor volume was calculated. Each data point is the average tumor volume in each group, and error bars represent standard deviation.

Triptolide treatment significantly inhibited tumor growth $(\mathrm{P}<0.05$; Fig. 8).

\section{Discussion}

There is still no standard therapeutic regimen to prevent breast cancer metastasis, the major cause of death in breast cancer patients (10-14). It is generally believed that tumor stem cells promote tumor metastasis in addition to increasing the recurrence risk and treatment resistance. There is now substantial evidence for the presence of stem cells in many tumor types, although definitive identification of these cells is still difficult. Current studies on tumor origins suggest that tumor stem cells are derived from native tissue stem cells or progenitor cells. If this cancer stem cell population does indeed facilitate metastasis, then targeted therapies may show substantial antitumor effects.

Only a minority of breast cancer cells have metastatic potency. In 2003, Al-Hajj et al (2) demonstrated that as few as $100 \mathrm{CD}^{2} 4^{+} \mathrm{CD} 24^{-/ \text {low/Lin }}{ }^{-}$cells were able to form tumors in immunodeficient nude mice. A subsequent series of 
studies indicated that tumorigenic breast cancer cells are $\mathrm{CD} 44^{+} \mathrm{CD} 24^{- \text {llow }}(15,16)$, consistent with other stem cells. At present, mammosphere cultivation, cell separation and selection culture and the aldehyde dehydrogenase 1 (ALDH1) assay are the most commonly used methods to identify stem cells. In this study, a special serum-free stem cell culture medium was used for suspension cultivation of mammospheres to select stem cells. The stem cell phenotype was then confirmed by surface antigen expression $\left(\mathrm{CD} 44^{+} \mathrm{CD} 24^{- \text {-low }}\right)$. In addition, these mammospheres expressed three transcription factors, sox 2 , nanog and oct 4 , characteristic of many pluripotent cells. After stem cells were cultured in DMEM with serum, the proportion of $\mathrm{CD} 44^{+} \mathrm{CD} 24^{- \text {llow }}$ cells decreased significantly and cells took on the morphological appearance of primary tumor cells, illustrating that stem cells can differentiate into cancer cells under appropriate conditions.

There is no effective treatment for preventing the genesis, development, recurrence, or metastasis of tumors $(17,18)$. To explore new treatment options, we examined the cytotoxicity of triptolide, a diterpenoid triepoxide extracted from the Chinese herb "common Threewingnut root" known to have antiinflammatory, immunosuppressant and antitumor effects (19). Triptolide can inhibit tumor growth and metastasis by inducing apoptosis and inhibiting neovascularization (20). Recently, triptolide was demonstrated to be a wide-spectrum tumor inhibitor with significant toxic effects on approximately 60 tumor types, including breast, gastric, epidermoid, bile duct, lung, pancreatic and bladder cancers, as well as granulocytic leukemia and melanoma. Triptolide induces apoptosis by activating the caspase pathway, inducing p53 expression and activating MAPK signaling $(21,22)$. Liu et al (3) found that triptolide upregulates wild-type p53 expression and inhibits mutant p53 expression. Triptolide does have side-effects, including reduced appetite, anorexia, vomiting, abdominal pain, diarrhea, esophageal irritation and leucopenia. However, these side-effects are generally reversible and dose-dependent.

In the present study, breast cancer stem cells extracted from human breast cancer tissue exhibited a significant doseand time-dependent sensitivity to the cytotoxic actions of triptolide. After $72 \mathrm{~h}, 1 \mu \mathrm{M}$ triptolide destroyed $65.6 \pm 5.2 \%$ of primary BCCs and $37.9 \pm 3.9 \%$ of BCSCs, while $56.5 \pm 4.6 \%$ of BCCs and $31.3 \pm 2.7 \%$ of BCSCs were undergoing apoptosis as indicated by Annexin V and PI staining. The proportion of dead cells was very similar to the proportion of apoptotic cells for both cancer cell types, suggesting that triptolide destroys tumor cells by inducing apoptosis. However, the cytotoxicity of triptolide was significantly weaker against BCSCs, consistent with the generally greater chemoresistance of stem cells compared to primary tumor cells. Nonetheless, this study confirms the substantial cytotoxicity of triptolide on breast cancer stem cells. Similarly, we demonstrated that in vivo triptolide was effective in controlling tumor growth.

In conclusion, triptolide can effectively kill primary breast cancer cells and breast cancer stem cells, at least in part by inducing apoptosis. This study provides a basis for further animal experiments investigating the therapeutic potential of triptolide and its derivatives against breast and other forms of cancer.

\section{References}

1. Bonnet D and Dick JE: Human acute myeloid leukemia is organized as a hierarchy that originates from a primitive hematopoietic cell. Nat Med 3: 730-737, 1997.

2. Al-Hajj M, Wicha MS, Benito-Hernandez A, Morrison SJ and Clarke MF: Prospective identification of tumorigenic breast cancer cells. Proc Natl Acad Sci USA 100: 3983-3988, 2003.

3. Liu J, Jiang Z, Xiao J, et al: Effects of triptolide from Tripterygium wilfordii on ERalpha and p53 expression in two human breast cancer cell lines. Phytomedicine 16: 1006-1013, 2009.

4. Lu L, Kanwar J, Schmitt S, et al: Inhibition of tumor cellular proteasome activity by triptolide extracted from the Chinese medicinal plant 'thunder god vine'. Anticancer Res 31: 1-10, 2011.

5. Yang S, Chen J, Guo Z, et al: Triptolide inhibits the growth and metastasis of solid tumors. Mol Cancer Ther 2: 65-72, 2003.

6. Pigneux A, Mahon FX, Uhalde M, et al: Triptolide cooperates with chemotherapy to induce apoptosis in acute myeloid leukemia cells. Exp Hematol 36: 1648-1659, 2008.

7. Zhou Y, Xu Q and Huang Y: An in vitro study of Triptolide inhibiting proliferation of vascular endothelial cells. Practical J China 6: 564-566, 2004.

8. Lou YJ, Jin J and Wang YG: Triptolide inhibits transcription factor NF-kappaB and induces apoptosis of multiple myeloma cells. Leuk Res 29: 99-105, 2005.

9. Alvi AJ, Clayton H, Joshi C, et al: Functional and molecular characterisation of mammary side population cells. Breast Cancer Res 5: R1-R8, 2003.

10. Chen Y and Rittling SR: Novel murine mammary epithelial cell lines that form osteolytic bone metastases: effect of strain background on tumor homing. Clin Exp Metastasis 20: 111-120, 2003.

11. Moltzahn FR, Volkmer JP, Rottke D and Ackermann R: 'Cancer stem cells' - lessons from Hercules to fight the Hydra. Urol Oncol 26: 581-589, 2008.

12. Liu S, Dontu G and Wicha MS: Mammary stem cells, selfrenewal pathways and carcinogenesis. Breast Cancer Res 7: 86-95, 2005.

13. Abraham BK, Fritz P, McClellan M, Hauptvogel P, Athelogou M and Brauch $\mathrm{H}$ : Prevalence of $\mathrm{CD} 44^{+} / \mathrm{CD} 24^{-/ \text {low }}$ cells in breast cancer may not be associated with clinical outcome but may favor distant metastasis. Clin Cancer Res 11: 1154-1159, 2005.

14. Ling LJ, Wang S, Liu XA, et al: A novel mouse model of human breast cancer stem-like cells with high CD $44^{+} \mathrm{CD} 24^{-/ \text {lower }}$ phenotype metastasis to human bone. Chin Med J 121: 1980-1986, 2008.

15. Ponti D, Costa A, Zaffaroni N, et al: Isolation and in vitro propagation of tumorigenic breast cancer cells with stem/progenitor cell properties. Cancer Res 65: 5506-5511, 2005.

16. Ginestier C, Hur MH, Charafe-Jauffret E, et al: ALDH1 is a marker of normal and malignant human mammary stem cells and a predictor of poor clinical outcome. Cell Stem Cell 1: 555-567, 2007.

17. Fan M, Yan PS, Hartman-Frey C, et al: Diverse gene expression and DNA methylation profiles correlate with differential adaptation of breast cancer cells to the antiestrogens tamoxifen and fulvestrant. Cancer Res 66: 11954-11966, 2006.

18. Eriksson M, Guse K, Bauerschmitz G, et al: Oncolytic adenoviruses kill breast cancer initiating $\mathrm{CD} 44^{+} \mathrm{CD} 24^{-/ \text {low }}$ cells. Mol Ther 15: 2088-2093, 2007.

19. Qiu D and Kao PN: Immunosuppressive and anti-inflammatory mechanisms of triptolide, the principal active diterpenoid from the Chinese medicinal herb Tripterygium wilfordii Hook. $\mathrm{f}$. Drugs R D 4: 1-18, 2003.

20. Yang S, Chen J, Guo Z, et al: Triptolide inhibits the growth and metastasis of solid tumors. Mol Cancer Ther 2: 65-72, 2003.

21. Frese S, Pirnia F, Miescher D, et al: PG490-mediated sensitization of lung cancer cells to Apo2L/TRAIL-induced apoptosis requires activation of ERK2. Oncogene 22: 5427-5435, 2003.

22. Zhang P, Zhang R and Wang Y: Research progress on the antitumor molecular mechanism of triptolide. Acta Chin Med Pharmacol 3: 79-82, 2009 (In Chinese). 